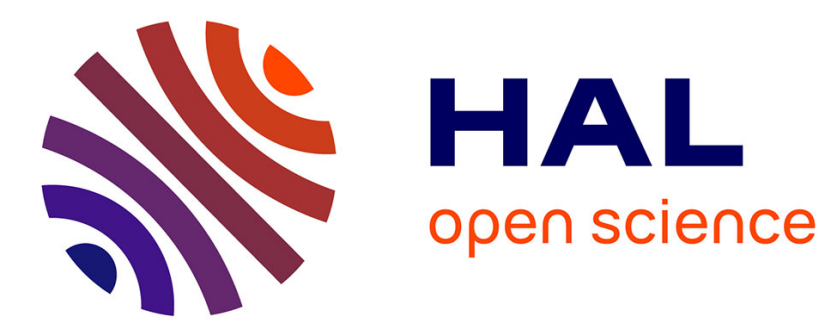

\title{
Macroscopic nature of brittle fracture
}

K. Wallin

\section{- To cite this version:}

K. Wallin. Macroscopic nature of brittle fracture. Journal de Physique IV Proceedings, 1993, 03 (C7), pp.C7-575-C7-584. 10.1051/jp4:1993795 . jpa-00252215

\section{HAL Id: jpa-00252215 https://hal.science/jpa-00252215}

Submitted on 1 Jan 1993

HAL is a multi-disciplinary open access archive for the deposit and dissemination of scientific research documents, whether they are published or not. The documents may come from teaching and research institutions in France or abroad, or from public or private research centers.
L'archive ouverte pluridisciplinaire HAL, est destinée au dépôt et à la diffusion de documents scientifiques de niveau recherche, publiés ou non, émanant des établissements d'enseignement et de recherche français ou étrangers, des laboratoires publics ou privés. 


\title{
Macroscopic nature of brittle fracture
}

\author{
K. WALLIN
}

Technical Research Centre of Finland, Metals Laboratory, P.O. Box 26, 02151 Espoo, Finland

The different possible mechanisms of cleavage fracture initiation are rather well known. It has been recognized that the critical steps for cleavage fracture are:

I Initiation of a microcrack eg. fracturing of a second phase particle.

II Propagation of this microcrack into the surrounding grains.

III Further propagation of the propagating microcrack into other adjacent grains.

Depending on temperature, loading rate and material, different steps are more likely to be most critical. Because materials generally are not uniform on a microscale, cleavage fracture initiation is a statistical event, which have implications upon the macroscopic nature of brittle fracture. In this presentation the macroscopic nature of brittle fracture will be examined and its impact upon the application of fracture mechanical material parameters for structural integrity evaluations will be discussed.

\section{INTRODUCTION}

The two main micromechanisms encountered in fracture resistance testing of most structural materials are ductile fracture and brittle cleavage fracture. There is a widely recognized view that ductile fracture proceeds by a continuous mechanism of microvoid nucleation and coalescence. Microvoid coalescence is a critical strain-controlled type of mechanisms. As such, it is strongly governed by the maximum strain state along the crack front. In order for the crack to propagate macroscopically, microvoid coalescence must occur along the whole crack front. The macroscopic fracture resistance to ductile fracture is thus governed by the mean toughness properties of the material. This means that for a macroscopically homogeneous material, the parameters related to ductile fracture $\left(\mathrm{J}_{\mathrm{IC}}, \mathrm{J}_{\mathrm{i}}, \delta_{\mathrm{i}}\right)$ should show only a small amount of scatter. Also, as long as the J-integral and crack-tip opening displacement describe the strains in front of the crack, the parameters should also be specimen size and geometry independent.

Brittle cleavage fracture differs completely in mechanism from ductile fracture. It is assumed that cleavage fracture is initiated by a, weakest link type, critical stress-induced mechanism, governed by locally situated cleavage initiators or "weak spots". As such, cleavage fracture will be affected, besides by changes in the stress distribution, also by the probability of finding a critical cleavage initiator. This weakest link type statistical nature of cleavage fracture unfortunately denote that fracture toughness in the case of cleavage fracture is not a simple material property. Firstly, cleavage fracture initiation toughness exhibits a large amount of scatter, and secondly, it shows a characteristic statistical size effect associated to the length of the crack front. Because of this statistical size effect one must always correct the 
experimental toughness values to correspond to the relevant crack front length. Presently testing standards do not make any separation between ductile and brittle fracture mechanisms. The biggest problem in fracture resistance determination is to select a proper fracture mechanical material parameter from the view of the structure. Preferable parameters to use are the parameters describing a true critical fracture event like ductile or brittle fracture initiation. However, one must also consider the consequences of appropriate fracture micromechanism in order to achieve an accurate assessment of the behaviour of the structure.

In this presentation the macroscopic nature of brittle fracture will be examined and its impact upon the application of fracture mechanical material parameters for structural integrity evaluations will be discussed.

\section{GENERAL STATISTICAL MODEL FOR CLEAVAGE FRACTURE INITIATION}

The different possible mechanisms of cleavage fracture initiation are rather well known. It has been recognized that the critical steps for cleavage fracture are:

I Initiation of a microcrack eg. fracturing of a second phase particle.

II Propagation of this microcrack into the surrounding grains.

III Further propagation of the propagating microcrack into other adjacent grains.

Depending on temperature, loading rate and material, different steps are more likely to be most critical. For structural steels at lower shelf temperatures and ceramics steps II and III are more difficult than initiation and they control the fracture toughness. At higher temperatures initiation becomes more difficult in relation to propagation and step I becomes more and more dominant for the fracture process. On the fracture surface this is usually seen as a difference in the number of initiation sites visible on the fracture surface. At lower shelf temperatures numerous initiation sites are visible, whereas at higher temperatures only one or two initiation sites can be seen. Because materials generally are not uniform on a microscale, cleavage fracture initiation is a statistical event, which have implications upon the macroscopic nature of brittle fracture.

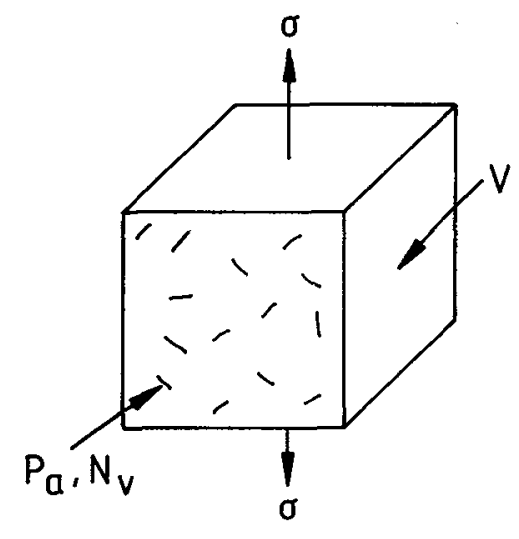

Fig. 1 Basis of the general statistical model [1]. 
The basis of the statistical model is presented in Fig. 1 [1]. It is assumed that the material in front of the crack contains a distribution of possible cleavage fracture initiation sites i.e. cleavage initiators. The cumulative probability distribution for a single initiator being critical can be expressed as $P\left(a \geq a_{c}\right)$ and it is a complex function of the initiator size distribution, stress, strain, grain size, temperature, stress and strain rate etc. The shape and origin of the initiator distribution is not important in the case of a "sharp" crack. The only necessary assumption is no global interaction between initiators. This means that interactions on a local scale are permitted. Thus a cluster of cleavage initiations may be required for macroscopic initiation. All the above factors can be implemented into the initiator distribution and they are not significant as long as no attempt is made to determine the shape of the distribution.

The cumulative failure probability of a volume element, with an uniform stress state, can be expressed as

$$
P_{f}=1-\left[1-P\left(a \geq a_{c}\right)\right]^{N v \cdot v}
$$

where $N_{v}$ is the number of initiators in unit volume and $V$ is the volume of the element.

Eq. 1 can also be rewritten as

$$
P_{f}=1-\exp \left\{V \cdot \ln \left[1-P\left(a \geq a_{c}\right)\right]^{N v}\right\}
$$

In the case of several independent homogeneous volume elements, with size $V_{i}$ having different states of stress the total cumulative failure probability becomes

$$
P_{f}=1-\exp \sum_{i=1}^{n} V_{i} \cdot \ln \left[1-P_{i}\left(a \geq a_{c i}\right)\right]^{N v}
$$

where $\mathrm{n}$ is the number of volume elements.

Eq. 3 contains one restricting assumption i.e. that the volume elements are homogeneous so that the number of initiators in a volume element is defined as : $N=N_{v} \cdot V$. In reality the initiators are randomly distributed, which causes $\mathrm{N}$ to be not constant but Poisson distributed [2]. If we mark the mean number of initiators with $\bar{N}$, the probability $P_{N}$ of having $N$ initiators in a volume element is

$$
P_{N}=\frac{\bar{N}^{N} \cdot \exp (-\bar{N})}{N !}
$$

The probability of initiation in one volume element becomes

$$
P_{f}=1-\sum_{N=0}^{\infty}\left[1-P\left(a \geq a_{c}\right)\right]^{N} \cdot P_{N}
$$

Performing the summation one obtains

$$
P_{f}=1-\exp \left\{\bar{N} \cdot\left[1-P\left(a \geq a_{c}\right)\right]\right\} \cdot \exp (-\bar{N})
$$

which reduces to

$$
P_{f}=1-\exp \left\{-\bar{N} \cdot P\left(a \geq a_{c}\right)\right\}
$$

Thus the form of eq. 3 , when assuming randomly distributed initiators, is 


$$
P_{f}=1-\exp \sum_{i=1}^{n}\left\{-\bar{N}_{v} \cdot V_{i} \cdot P_{i}\left(a \geq a_{c i}\right)\right\}
$$

where $\bar{N}_{v}$ is the mean number of initiators per unit volume.

If the probability of an initiator being critical is smaller than 0.1 eqs. 3 and 8 are practically identical. Because the probability of an initiator being critical is usually much smaller than 0.1 it is really arbitrary which form to use.

It should be emphasized that the above expressions contain no approximations.

For a "sharp" crack in small scale yielding the stresses and strains are described by a specific field. One property of this field is that the stresses have an angular dependence. Thus the stress field can be divided into small fan like elements with an angle increment $\Delta \theta$. In this case the cumulative failure probability becomes

$$
P_{f}=1-\underset{\theta=0}{\exp \sum}\left\{\sum_{x=0}^{x_{p}}-\bar{N}_{v} \cdot B \cdot \Delta x \cdot x \cdot \sin (\Delta \theta) \cdot P\left(a \geq a_{c}\right)\right\}
$$

where the volume element in the $\mathrm{x}$-direction, described by $\Delta \mathrm{x}$ must be clearly larger than the initiator size a. The double summation indicates that the summation is performed over the whole plastic zone.

Due to the properties of the sharp crack stress field it is possible to normalize the distance with the stress intensity factor

$$
\mathrm{U}=\frac{\mathrm{x}}{\left(\mathrm{K}_{\mathrm{I}} / \sigma_{\mathrm{y}}\right)^{2}}
$$

When eq. 10 is inserted into eq. 9 the cumulative failure probability becomes

$$
\mathbf{P}_{\mathrm{f}}=1-\exp \left\{\mathbf{B} \cdot \sin (\Delta \theta) \cdot \frac{\mathrm{K}_{\mathrm{I}}^{4}}{\sigma_{\mathrm{y}}^{4}} \cdot \sum_{\theta=0}^{2 \pi}\left(\sum_{\mathrm{U}=0}^{\mathrm{U}_{\mathrm{P}}}-\overline{\mathbf{N}}_{\mathrm{v}} \cdot \mathrm{U} \cdot \Delta \mathrm{U} \cdot \mathrm{P}\left(\mathrm{a} \geq \mathrm{a}_{\mathrm{c}}\right)\right)\right\}
$$

The result of the double summation is always negative and independent of $\mathrm{K}_{\mathrm{r}}$. This enables us to write

$$
\mathrm{P}_{\mathrm{f}}=1-\exp \left[\text {-const. } \cdot \mathrm{B} \cdot \mathrm{K}_{\mathrm{I}}^{4}\right]
$$

Essentially the same equation has been derived separately by numerous investigators [3-8]. It is seen that the scatter of fracture toughness is really independent of the cleavage initiator distribution. The result contains no approximations. The only assumption is that the initiators are independent on a global scale. In other words it is assumed that the volume elements are independent for a constant $K_{1}$. Only, if it is assumed that a certain fraction of the crack front must experience critical initiations to cause macroscopic failure, then the result will differ from eq. 12. In the derivation, the cleavage fracture process zone was assumed to be equal to the plastic zone. Eq. 12 is, however, not sensitive to the definition of the process zone as long as it is assumed that the process zone size correlates with $\mathrm{K}_{\mathrm{I}}$, CTOD or J. It is interesting to note that eq. 12 is identical to the Weibull distribution function with a fixed value for the shape parameter. The result is not, however, related to Weibull statistics in any way but to assume a weakest link type failure mechanism. 


\section{CONDITIONAL CRACK PROPAGATION CRITERIA}

Eq. 12 would imply that an infinitesimal $K_{I}$ value might lead to a finite failure probability. This is not true in reality. For very small $\mathrm{K}_{\mathrm{I}}$ values the stress gradient becomes so steep that even if cleavage fracture can initiate it cannot propagate into the surrounding and other adjacent grains, thus causing a zone of microcracks in front of the main crack. If propagation in relation to initiation is very difficult a stable type of fracture may evolve. This is an effect often seen with ceramics. The need for propagation lead to a conditional crack propagation criteria, causing a lower limiting $\mathrm{K}_{\min }$ value below which cleavage fracture is impossible. For structural steels at the lower shelf temperature range, the fracture toughness is likely to be the controlled by the inability of propagation.

The question regarding propagation alters the above pure weakest link type argument somewhat. It means that initiation is not the only requirement for cleavage fracture, but additionally a conditional propagation requirement must be fulfilled. David Stienstra [9] has shown that, when the conditional propagation requirement is implemented into the weakest link based eq. 12 , the cumulative failure probability will be of the form

$$
\mathrm{P}_{\mathrm{f}}=1-\exp -\int_{\mathrm{K}_{\min }}^{\mathrm{K}} f(\mathrm{P} / \mathrm{I}) \cdot \frac{\mathrm{B}}{\mathrm{B}_{0}} \cdot \frac{4 \cdot \mathrm{K}^{3}}{\boldsymbol{\theta}^{4}} \cdot \mathrm{dK}
$$

where $f(\mathrm{P} / \mathrm{I})$ is the conditional probability of crack propagation and $\theta$ is a scaling parameter equal to the constant in eq. 12 .

Stienstra modelled $f(\mathrm{P} / \mathrm{I})$ as a power law [9]. Other forms of $f(\mathrm{P} / \mathrm{I})$ are, however, also possible. Intuitively, it appears that the probability of crack propagation must be controlled by the steepness of stress distribution. Considering the shape of the stress distribution it can be shown that the steepness $\left(\mathrm{d} \sigma_{\mathrm{yy}} / \mathrm{dx}\right)$ is related to $1 / \mathrm{K}^{2}$. Thus possible forms for $f(\mathrm{P} / \mathrm{I})$ are e.g.

$$
f(\mathrm{P} / \mathrm{I})=\mathrm{A} \cdot\left\{1-\mathrm{K}_{\min } / \mathrm{K}\right\}^{2}
$$

or

$$
f(\mathrm{P} / \mathrm{I})=\mathrm{A} \cdot\left\{1-\left(\mathrm{K}_{\min } / \mathrm{K}\right)^{2}\right\}
$$

where $\mathrm{A}$ is a constant recognizing that there will always be a finite probability of microscopic crack arrest.

Integration of eq. 13 applying eqs. $14 \mathrm{a}$ and $14 \mathrm{~b}$ yield respectively

$$
\mathrm{P}_{\mathrm{f}}=1-\exp -\left\{\text { const. } \cdot \mathrm{B} \cdot\left(\mathrm{K}-\mathrm{K}_{\min }\right)^{3} \cdot\left(\mathrm{K}-\mathrm{K}_{\min } / 3\right)\right\}
$$

and

$$
\mathrm{P}_{\mathrm{f}}=1-\exp -\left\{\text { const. } \cdot \mathrm{B} \cdot\left(\mathrm{K}^{2}-\mathrm{K}_{\min }{ }^{2}\right)^{2}\right\}
$$

The best experimental verification has been obtained for a three parameter Weibull type equation of the form $[1,10-14]$.

$$
P_{f}=1-\exp -\left\{\text { const. } \cdot B \cdot\left(K-K_{\min }\right)^{4}\right\}
$$


This equation imply a conditional propagation function of the form

$$
f(\mathrm{P} / \mathrm{I})=\mathrm{A} \cdot\left\{1-\mathrm{K}_{\min } / \mathrm{K}\right\}^{3}
$$

When eq. 16 is rewritten as

$$
\left\{\log \left[1 /\left(1-\mathrm{P}_{\mathrm{f}}\right)\right]\right\}^{1 / 4}=\text { const }_{1} \cdot\left(\mathrm{K}-\mathrm{K}_{\min }\right)
$$

the result will be a straight line starting at $\mathrm{K}_{\min }$ and having a slope proportional to the normalization constant. In order to compare the new equations $15 \mathrm{a}$ and $15 \mathrm{~b}$ with the more experimental equation 16 , the equations $15 \mathrm{a}$ and $15 \mathrm{~b}$ have been plotted in the normalized co-ordinate system defined by eq. 18 . The results of the comparisons are presented in Figs 2 and 3.

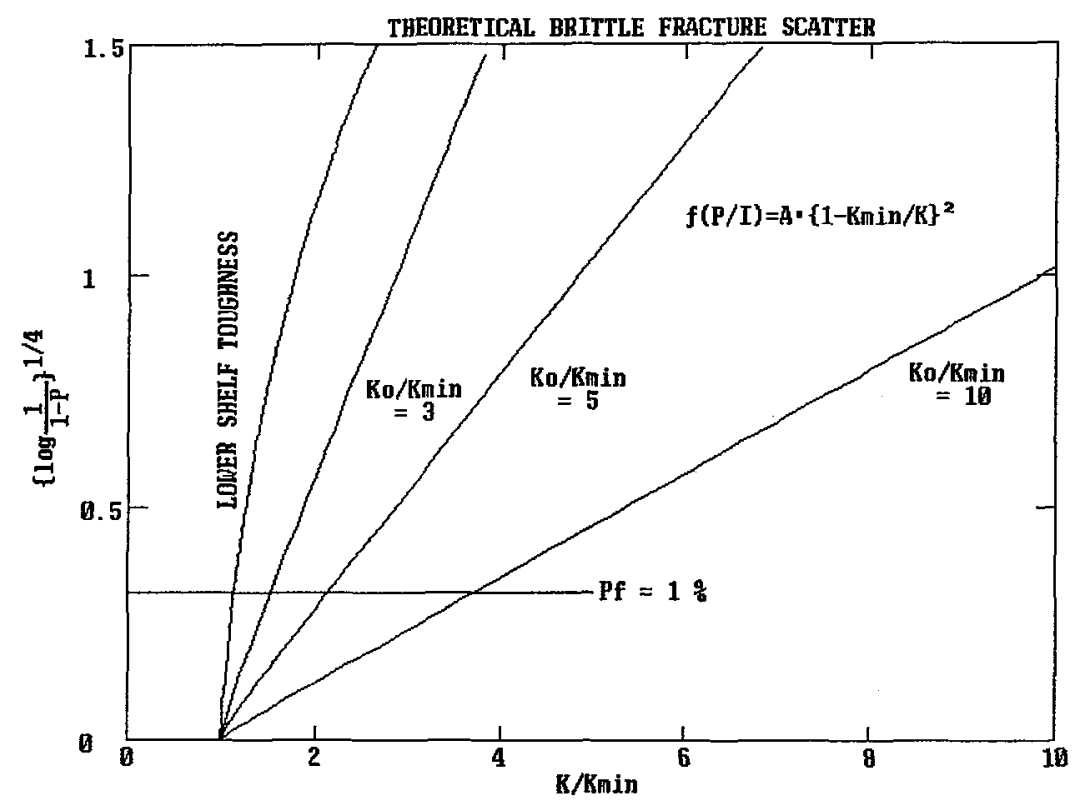

Fig. 2 Failure probability diagram describing the scatter in brittle fracture toughness based on conditional probability of crack propagation according to eqs. 14a and 15a. The constant in eq. $15 \mathrm{a}$ has been denoted $\left(\mathrm{K}_{0}-\mathrm{K}_{\min }\right)^{-4} / \mathrm{B}$.

The figures contain also a line denoted lower shelf toughness. This correspond to a material state where the probability of initiation is essentially infinite i.e. independent of $\mathrm{K}$. In this state the fracture probability is only a function of the probability of propagation.

In the figures, the $1 \%$ failure probability limit has been included. This correspond basically to the lower bound probability level that can be reached experimentally. Concentrating only on the parts of the curves corresponding to a higher failure probability than $1 \%$ reveal that it is actually impossible to differentiate between eqs. 15a, 15b and 16. Even though the distributions defined by eqs. 15a and 15b would be physically more justified than eq. 16, there is no factual difference between the distributions. The distribution yielding the most conservative estimate of the lower limiting fracture toughness is eq. 16 and therefore its' use is justified. Additionally eq. 16 has the simplest form of the different distributions. 


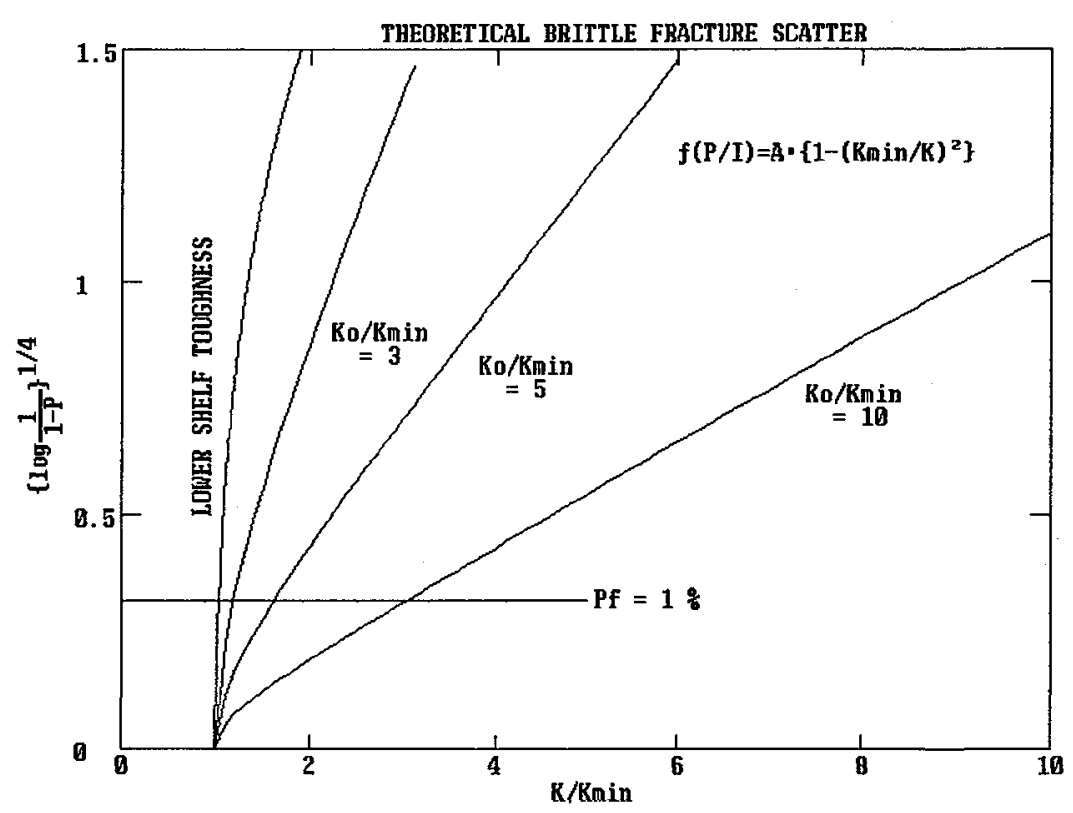

Fig. 3 Failure probability diagram describing the scatter in brittle fracture toughness based on conditional probability of crack propagation according to eqs. $14 \mathrm{~b}$ and $15 \mathrm{~b}$. The constant in eq. $15 b$ has been denoted $\left(K_{0}-K_{\min }\right)^{-4} / B$.

\section{DISCUSSION}

The answer regarding which (if any) of the functions describing the conditional probability of propagation is most realistic is not clear. Stienstra applied a micromechanism based propagation criteria to calculate the conditional probability as a function of $K$ [9]. Perhaps not surprising, eq. 14b yield the best resemblance to Stienstra's calculations (Fig. 4). This would indicate that eq. 15 b should be the physically most sensible form of distribution. If the fracture toughness is presented in the form of the J-integral or the crack tip opening displacement eq. $15 \mathrm{~b}$ is simplified to

$$
P_{\mathrm{f}}=1-\exp -\left\{\text { const. } \cdot \mathrm{B} \cdot\left(\mathrm{J}-\mathrm{J}_{\min }\right)^{2}\right\}
$$

or

$$
\mathrm{P}_{\mathrm{f}}=1-\exp -\left\{\text { const. } \cdot \mathrm{B} \cdot\left(\delta-\delta_{\min }\right)^{2}\right\}
$$

which is quite an elegant form of distribution function.

The weakness with eqs. 19a-b is that the limiting fracture toughness is practically impossible to estimate either analytically or experimentally. The use of eq. 17 is supported by the fact that the so defined $\mathrm{K}_{\min }$ appears to be quite material insensitive $[1,10,10,14]$. For structural steels a constant value of $20 \mathrm{MPa} \sqrt{\mathrm{m}}$ has been successfully applied for a wide range of temperatures.

If the ratio between the mean fracture toughness $\overline{\mathrm{K}}$ and $\mathrm{K}_{\min }$ is larger than 3 then the ratio $\quad \overline{\mathrm{J}} / \mathrm{J}_{\min }>9$ and $\mathrm{J}_{\min }$ looses its' significance. With the exception of the lower shelf, $\mathrm{J}_{\min }$ and $\delta_{\min }$ can well be ignored. 


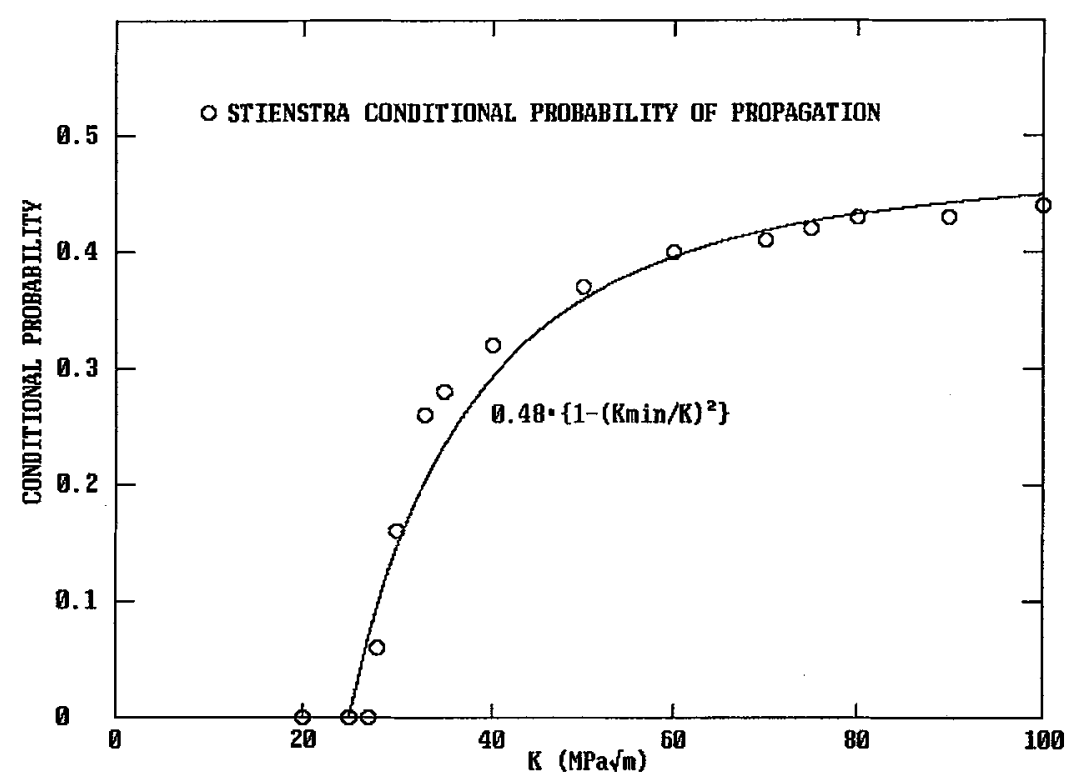

Fig. 4 Comparison of Stienstra's calculated conditional probability of propagation with eq. $14 \mathrm{~b}$.

A comparatively comprehensive data set corresponding to the lower shelf temperature range has been generated by McCabe [15] for a pressure vessel steel corresponding to three different specimen sizes. His data has been presented in Fig. 5. The interesting fact with the data is that it does not implicate a statistical size effect such that large specimen would yield lower toughness values than small specimens. If any, the effect appears to be the opposite. This indicates that the fracture toughness in this case really is propagation controlled. In Fig. 5 have also been included the resulting failure probability distributions applying eqs. $14 \mathrm{a}, 14 \mathrm{~b}$ and 17 . Surprisingly, eq. $14 \mathrm{~b}$ does not appear superior in relation to the other eqs. Actually, the maximum probability of propagation must be set to only $22 \%$ in order for the equation to describe the test results. From this point of view the other eqs. appear more realistic.

In reality there are not significant differences between the three different distribution functions. The same is to be expected with other expressions for the conditional probability of propagation that are able to describe actual experimental data. The present findings support the validity of eq. 16 for describing the macroscopic scatter of fracture toughness in the case of brittle fracture. The fact that eq. 16 yield a lower limiting fracture toughness than eqs. $15 \mathrm{a}$ and $15 \mathrm{~b}$ also speak strongly in favor of using eq. 16 . Even on the lower shelf where brittle fracture is propagation controlled, eq. 16 yield a satisfactory representation of the true cumulative failure distribution and a conservative estimate of the lower bound fracture toughness. The present analysis is valid as long as the specimens do not experience large scale yielding or ductile tearing. When such events occur they will affect the brittle fracture probability and the analysis becomes much more difficult.

Eqs. 15a, 15b and 16 all indicate a statistical size effect, which will be slightly different for the various distributions. The two most differing eqs. (15b and 16) have been plotted as a function of thickness corresponding to three different toughness levels in Fig. 6 . The differences in the two distributions on the statistical size effect are seen to be quite insignificant in magnitude. Thus, also the statistical size effect is well described by eq. 16 . 


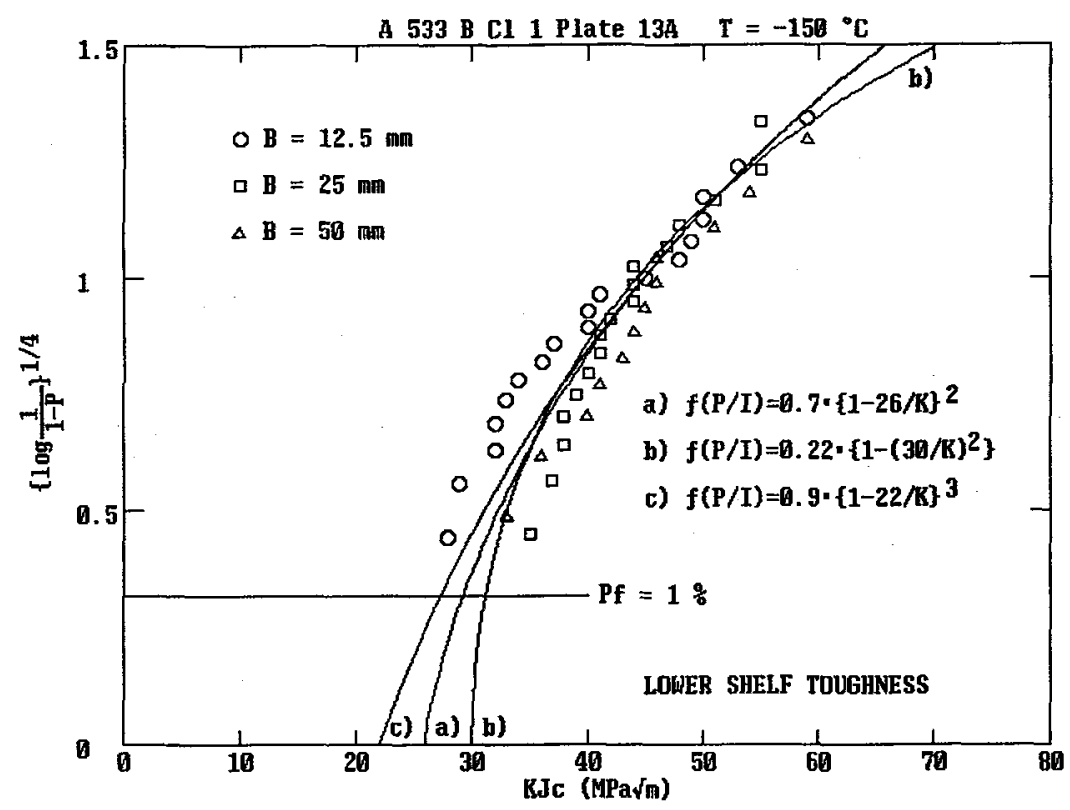

Fig. 5 Scatter in brittle fracture toughness test results at the lower shelf [15] compared with predictions based on the conditional probability for crack propagation criteria.

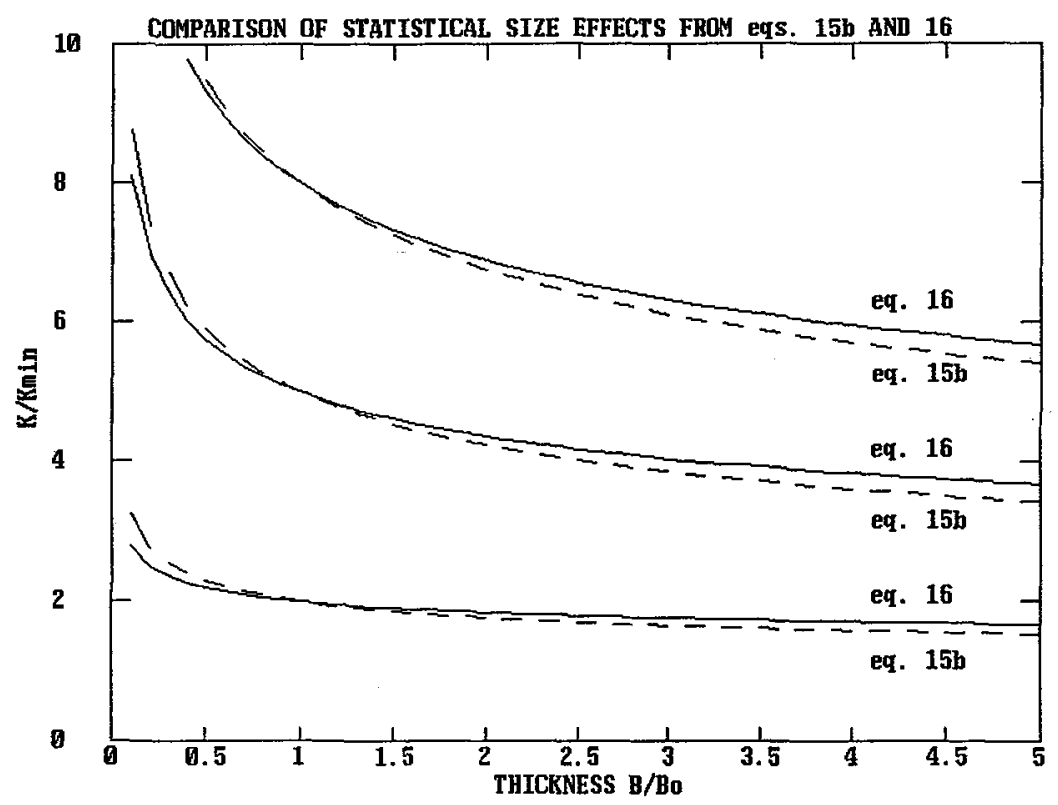

Fig. 6 Comparison of statistical size effects evolving from eqs. $15 \mathrm{~b}$ and 16. 


\section{SUMMARY AND CONCLUSIONS}

The macroscopic nature of brittle fracture has been examined based on simple micromechanism based statistical models. Based on the examination the following conclusions can be drawn regarding the macroscopic nature of brittle fracture:

The fracture toughness has, in the case of brittle fracture a specific scatter distribution which can be described by the cumulative failure probability distribution $P_{\mathrm{f}}=1-\exp -\left\{\right.$ const. $\left.B \cdot\left(\mathrm{K}-\mathrm{K}_{\min }\right)^{4}\right\}$.

The specific scatter distribution indicate a distinct specimen size (crack front length) effect.

On the lower shelf, where propagation is dominant over initiation, statistical specimen size effects may disappear, but from a structural integrity assessment point, it is better to assume the size effects to exist also on the lower shelf.

The present findings are valid for structural steels failing by cleavage fracture and brittle ceramics.

In the ductile to brittle transition region the additional effects of large scale yielding and ductile tearing must be addressed.

\section{ACKNOWLEDGEMENT}

This work is a part of the Nuclear Power Plant Structural Integrity Programme performed at the Technical Research Centre of Finland (VTT) and financed by the Ministry of Trade and Industry in Finland.

\section{RFERENCES}

[1] WALLIN K., Defect Assessment in Components - Fundamentals and Applications, ESIS/EGF9, 1991, pp. 415-445.

[2] BRÜCKNER-FOIT A., MUNZ D. and TROLLDENIER B., Arbeitsbericht zum DFG Vorhaben "Sprödbruch" MU466/14-1, für den Zeitraum vom 1.07.1987-31.12.1988. Institut für Zuverlässigkeit und Schadenkunde im Maschinenbau, Universität Karlsruhe (TH), Karlsruhe 1989, 45 p. (In German).

[3] PINEAU A., Advances in Fracture Research, 5th International Conference on Fracture, 2, 1981, pp. 553-577.

[4] BEREMIN F. M., Met. Trans., 14A, 1983, pp. 2277-2287.

[5] WALLIN K., SAARIO T., TÖRRÖNEN K. AND FORSTÉN J., Technical Research Centre of Finland, Research Reports 220, Espoo 1983, 15 p.

[6] SLATCHER S., Fatigue \& Frac. of Eng. Mat. \& Struc., 9, 1986, pp. 275-289.

[7] TYSON R. T. and MARANDET B., Fracture Mechanics: Eighteenth Symposium, ASTM STP 945, 1988, pp. 19-32.

[8] ANDERSON T. L., Nonlinear Fracture Mechanics: Vol. II - Elastic-Plastic Fracture, ASTM STP 995, 1989, pp. 563-583.

[9] STIENSTRA D., Ph.D. dissertation, Texas A\&M University, 1990, 252 p.

[10] WALLIN K., Engng. Frac. Mech., 19, 1984, pp. 1085-1093.

[11] WALLIN K., Engng. Frac. Mech., 22, 1985, pp. 149-163.

[12] WALLIN K., Engng. Frac. Mech., 32, 1989, pp. 523-531.

[13] WALLIN K., Engng. Frac. Mech., 32, 1989, pp. 449-457.

[14] WALLIN K., Constraint Effects in Fracture, ASTM STP 1171, 1993, pp. 264-288.

[15] McCABE D., Personal communication. 